\title{
Research on Modularization and Sustainable Design of Temporary Housing
}

\author{
Hui Yu, Ge Bai \\ School of Architecture and Fine Art, Dalian University of Technology, Dalian, China \\ Email: 517964304@qq.com
}

How to cite this paper: $\mathrm{Yu}, \mathrm{H}$. and Bai, G. (2018). Research on Modularization and Sustainable Design of Temporary Housing. Art and Design Review, 6, 125-132. https://doi.org/10.4236/adr.2018.63012

Received: June 7, 2018

Accepted: June 31, 2018

Published: August 3, 2018

Copyright $(9) 2018$ by authors and Scientific Research Publishing Inc. This work is licensed under the Creative Commons Attribution International License (CC BY 4.0).

http://creativecommons.org/licenses/by/4.0/

\begin{abstract}
Temporary housing is temporary houses relative to permanent fixed housing. Due to temporary and inefficient factors of temporary housing, people pay less attention to it. Temporary housing has many problems such as single space mode, chaotic function, low comfort, poor ecological efficiency and so on. This research is faced with the growth of human society, the emergency response of natural disasters, the sustainability of production and construction, and the comfort of temporary residence. The design realized the requirements of factory production, folding loading and unloading, clear functional space about temporary housing through modular design, meets higher comfort requirements of housing. At last, strategic reserve and repeated use enhance the ecological sustainability of products.
\end{abstract}

\section{Keywords}

Sustainability, Temporary Housing, Modularization

\section{Introduction}

Temporary housing is temporary houses relative to permanent fixed housing. It plays a major role in disaster relief and housing shortage among the global environment due to the advantages such as small occupied space, rapid installation, and low cost. Its main application includes: first, temporary housing can be used for the resettlement of residents after natural disasters, which is an important factor in rebuilding social order, stabilizing people's hearts and reconstructing confidence in life. Second, temporary housing can be used for temporary use in urban construction, with a total number of $1-2$ persons. Third, temporary housing can meet the needs of construction and operation of workers far away from the city, so as to provide convenient temporary accommodation for them. Fourth, in order to promote the global humanitarian spirit, temporary housing has effectively improved the problem of refugee resettlement in poor countries, 
providing them with safe and comfortable shelters. However, due to the temporary and inefficient factors of temporary housing, people do not pay enough attention to it. This research analyses the advantages and disadvantages of several temporary houses such as tents, assembly plate house and container houses. With the analysis and comparison and the simulation experiment, the folding modular temporary housing model is designed and researched, and the combination form, the use mode and the value of temporary housing are analyzed and verified. And this study discusses the design patterns that meet the high comfort requirements of living and to enhance the ecological sustainability of temporary housing.

\section{Analysis of the Advantages and Disadvantages of Different Types of Temporary Housing}

"Housing" is the basic place of human life. If there's no complete living space and comfortable living conditions, residents will affected by both physical and psychological factors for a long time. However, due to the lack of systematic sustainable design, there are many problems such as single space mode, chaotic function, low comfort, poor ecological efficiency and so on (Kang \& Li, 2013). However, the lack of identifiability and privacy will inevitably lead to peoples' psychological exclusion. As the time goes on, it is likely to lead a dispute between the resident (Zhang, Wang, \& Zhao, 2008). Therefore, it is particularly important to improve the comfort of temporary housing so as to meet the needs of different functions.

Temporary housing includes tents, assembly plate houses and container houses (Yu \& Liu, 2009). The tent has the advantages of small storage volume, easier emplacement, rapid installation, low cost, reutilization and so on. However, there are also disadvantages such as poor ability to resist bad weather, single function space, poor housing and hygiene conditions, it's not good for long time use. Assembly plate houses can install assembled function fast, and it has relatively complete function space. But its material cost is high, the construction process needs professional construction team. After recycling, the utilization value is not high enough to reuse. It's also needs huge amount of money to support. As a new sustainable housing in recent years, container houses can solve the housing problem quickly. The integrity of container houses is good, it also has strong seismic and deformation resistance. At the same time, it can convenient disassembly and assembly, and it has good sealing performance. It also can be directly placed on the terrace with better drainage conditions. The manufacturing of containers is based on a uniform international standard of $3050 \mathrm{~mm} \times$ $2438 \mathrm{~mm} \times 2500 \mathrm{~mm}$ or $12192 \mathrm{~mm} \times 2438 \mathrm{~mm} \times 2591 \mathrm{~mm}$ (Tang, 2008), the layout and use of functional space are limited to some extent.

\section{The Features of Modularization and Sustainable Temporary Housing}

Tents, assembly plate houses and container houses can not satisfied the good sa- 
nitary conditions and perfect personal privacy. At the same time, the living mode and bad sanitary conditions in this environment can easily lead to the spread of disease. Modularization and sustainable temporary housing summarizes the advantages of the temporary housing, realizes factory production, folding and disassembly. It also takes account of environment, human psychology, and other aspects so as to create a complete functional space for life. First, modularization design of the functional space of temporary housing not only improves the speed of construction, but also facilitates the rapid assembly of construction sites. Second, the functional space of the temporary housing is complete to meet the needs of peoples' basic comfort and privacy, and modular production can be done according to the function of the house at the same time. Third, temporary housing is sustainable to satisfy the repeated use of residents, it also can improve the efficiency of production and storage, and finally reduce costs by recycling. Fourth, temporary housing has high efficiency of installation. Modular sustainable temporary housing has small storage space, but large unfolded space to meet daily activities. On the other hand, it has the characteristics of installation and assembly integration, which is similar to IKEA's home. It effectively saves space and manpower. Above all, the modular sustainable temporary housing is easy to assemble, and the factory prefabricates the collapsible structure. Ordinary residents can use simple tools to complete the house and put into use. In 1997, when summing up Los Angeles' experience in reconstruction, the California government of the United States put forward an important proposal: reduce the construction of temporary shelters and transitional resettlement houses, then build the permanent and simple housing for the affected residents directly so that the disaster victims can return to normal life more quickly (Li, 2008). While the modularization and sustainable temporary housing has greatly improved the residential function of temporary housing, and realized the sustainable reuse of temporary housing so as to satisfy the higher economic requirements.

\section{Design and Discussion}

\subsection{Complete Functional Space Module}

The modularization and sustainable temporary housing in the design consists of a fixed living space module and a folding enclosure plate. The external dimension of the folding factory prefabricated housing module is $1.35 \mathrm{~m} \times 2.7 \mathrm{~m} \times 2.7$ $\mathrm{m}$ (wide $\times$ long $\times$ high), divided into bedrooms, kitchen rooms and toilets, which are isolated by folding and sealed plates to form a relatively independent space. The bedroom is located at one end of a folding factory prefabricated housing module. The kitchen is located at the other end of the bedroom. The bedroom and the kitchen are used to make use of the fixed structure of the part of the main body. The toilet is located in the main fixed structure of the folding factory prefabricated housing module. The space of the fixed structure is divided into two layers and the upper layers are divided by several clapboard. Lower 
layer space meets the needs of toilet and other sanitary ware. The upper space is the kitchenware module, which is stored in the upper space through the shaft parts. And it is connected to the upper and lower levels so as to meet the use of toilet (Figure 1 \& Figure 2). Modular interior prefabricated folding bed, sanitary ware, overall cabinet and other necessities of life. There is a built-in high strength plastic toilet box under the toilet module floor, which is used before the completion of the urban water supply and sewage system. After the repair is completed, the toilet drain pipe can be directly connected to the urban sewage system.

\subsection{Diverse Forms of Combination}

Modular production can improve the efficiency of production and use, and reduce the costs of production and storage. The fixed living space module meets the needs of different functions, on the other hand, it is an important structural component of the modularization housing unit, which has the function of stabilizing the whole unit and supporting the roof enclosure. The wall, floor, roof and other outer protecting plates of the housing use light and high strength insulation materials, through standardized production mode, the modularized temporary residential unit is realized, and the process of installation and disassembly is simplified to the best (Figure 3). The basic size of the guard board is $1 \mathrm{~m} \times 2.7 \mathrm{~m}$ (width $\times$ height), and is stored in fixed space modules in the form of folding. After the simplest folding module unit is unfolded, it can form a basic set of

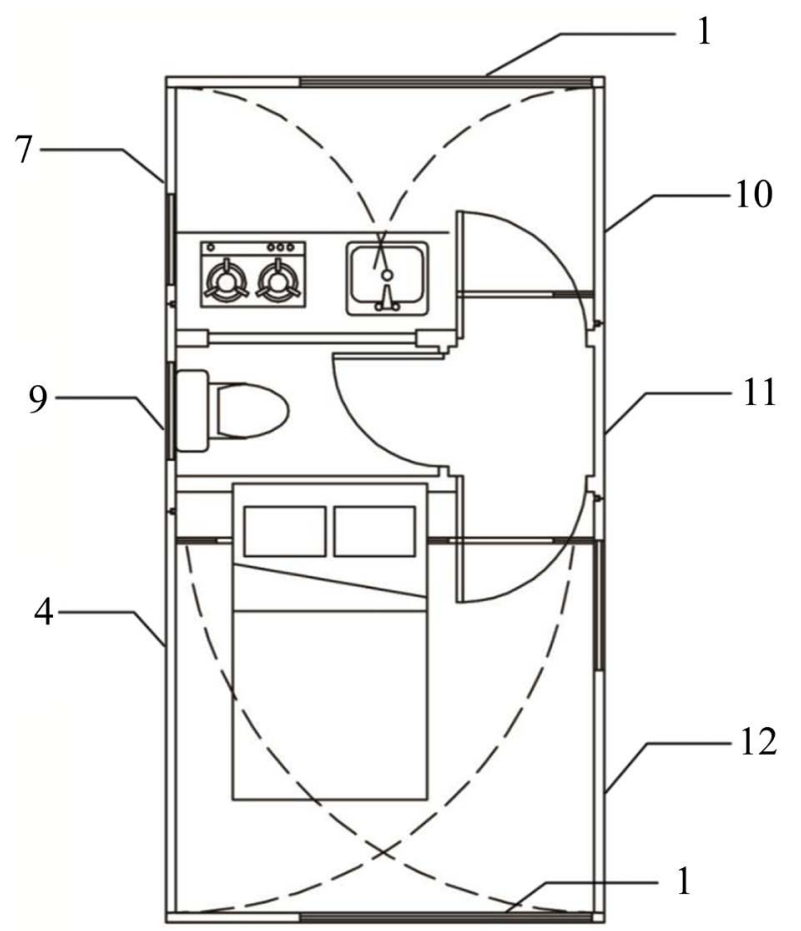

Figure 1. Plan of combined unit. 1: window; 4: Left backside wallboard; 7: Right backside wallboard; 9: Middle backside wallboard; 10: Right front wall board; 11: Middle front wallboard; 12: Left front wall board. 


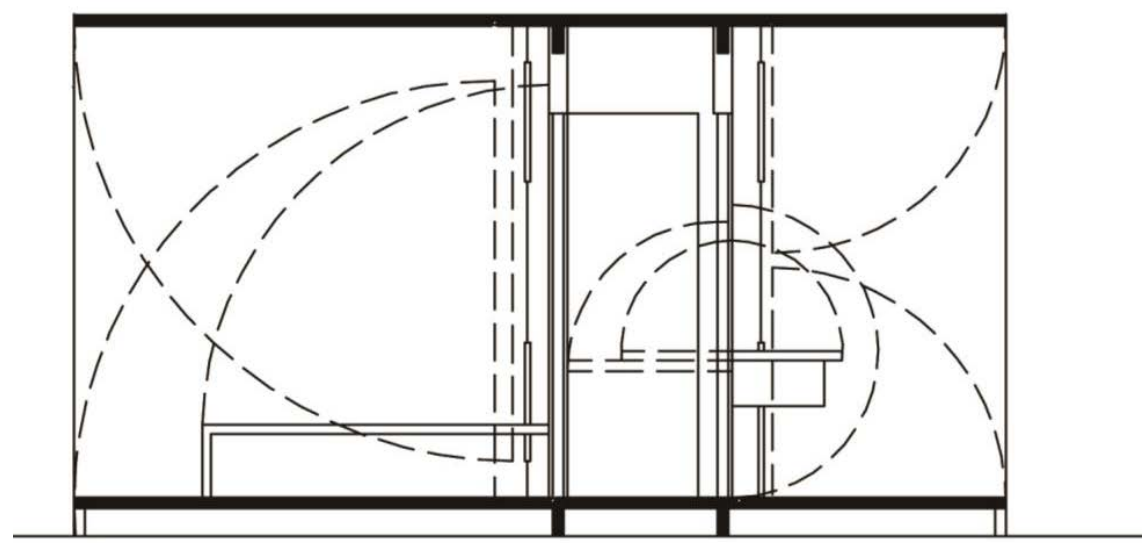

Figure 2. Section plan of combined unit.

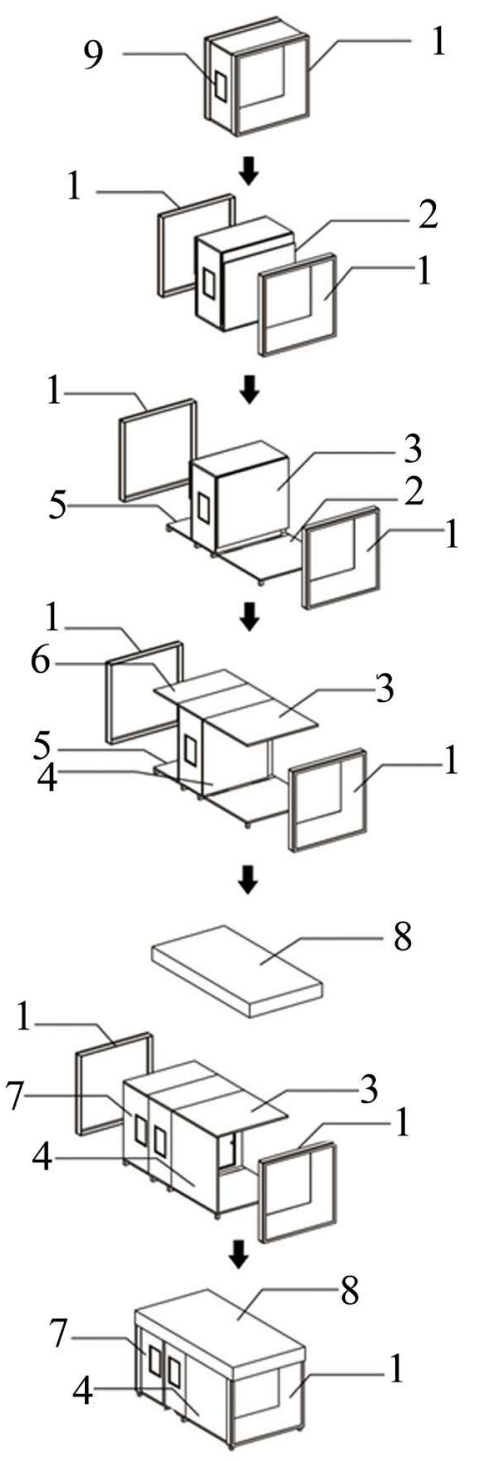

Figure 3. Isometric view of combined unit. 1: window; 2: left baseplate; 3: left apical plate; 4: Left backside wallboard; 5: right baseplate; 6: right apical plate; 7: Right backside wallboard; 8: Roof tarpaulin; 9: Middle backside wallboard. 
housing with an area of $21.7 \mathrm{~m}^{2}$, with basic functional spaces such as bedrooms, toilets, showers, kitchens, and living rooms. The folding module can be expanded according to the needs of space. As shown in the picture, the pattern of bed retracting enhances the space utilization rate, which turn bedroom into living room (Figure 4).

Through the full industrial production of modular units, the design has realized simple assembly, transportation, storage, recycling and reuse, which greatly improved the residential function of modularization housing, realized the sustainable reuse of modularization housing, and thus met the higher economic requirements.

\subsection{Simple and Fast Assembly and Disassembly Mode}

Except the guarantee of perfect use, this modularization housing will also meet the simple and rapid assembly, and even do not rely on the professional workers, and can complete the assembly and disassembly by using simple tools.

We should expand the factory prefabricated housing module in the folded state when it needs to use. First of all, rotate the cooker around the shaft 180 degrees, through the reserved square hole, fixed to the middle back panel. Then, the sealing plate is rotated around the shaft to form closed bathrooms and kitchens. The toilet is equipped with integrated upper water and sewage pipe, and the reserved interface is under the bottom board. If the condition is available, it can be directly connected to the urban pipe network. If not, in order to use conveniently and temporarily, it should predeposited light plastic water storage

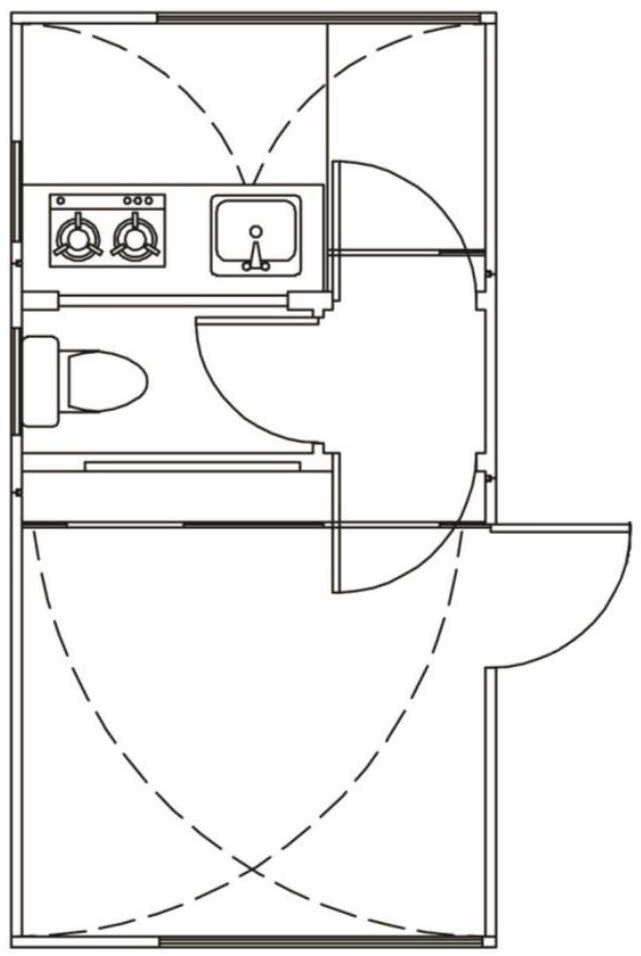

Figure 4. The pattern of bed retracting. 
tank and the sewage tank in the toilet. The side wall panels folded through a shaft, which can open vertically and horizontally, forming the square bedroom and the kitchen. The open side walls are fixed through bolts and pins, the gap between them sealed through a u-shaped or l-shaped interface and embedded tape. A folding seat reserved for the outer side of the floor, and the indoor ground maintenance level can be adjusted according to the site conditions. Prefabricate plexiglass windows can be fixed directly on both ends of the building to form a luminous walls. A bedplate that can fold around a shaft can be reserved on the outer side of the bedroom, which can be form furniture after expanded. Thus, the entire modularization housing will be extended to normal residential use.

After the use of modularization housing, firstly we should remove both ends of the box wall panels, and then fold the retaining boards around the shaft according to the order of expanded. So as to return to factory prefabricated housing module with a size of $2.7 \mathrm{~m} \times 1.8 \mathrm{~m} \times 2.7 \mathrm{~m}$ (length $\times$ width $\times$ height). At last, we can use the box cover board which was removed before to seal the both ends, it can be sterilized and stored, achieving the effect of recycling reuse.

\subsection{Easy to Recycle, Reserve and Reuse}

The design, production and use of modularization housing for sustainable use should follow the principle of sustainable development. While easy to assemble, it is also easy to disassemble. After a number of damaged and missing components are supplemented and repaired, unit housing can be restored to 3 module storage units for next use. The storage capacity of such a housing is $1.35 \mathrm{~m} \times 2.7$ $\mathrm{m} \times 2.7 \mathrm{~m}$. Reusable can effectively reduce construction costs, avoid waste and modularization housing demolition, thus accelerate the reconstruction speed.

\section{Conclusion}

In recent years, temporary housing has played an important role in disaster relief and housing shortage in the global environment, for example, in the rescue work after the Hanshin-Awaji-daishinsai earthquake in Japan, the construction of temporary housing is completed within 40 days according to the time limit for the disaster in order to meet the basic use of the victims. Within 100 days after the Wenchuan earthquake in China, the government and the relevant departments provided 1 million temporary housing to ensure the temporary use of the victims. In a word, the development and practice of modularization and sustainable design of temporary housing should be paid attention to. The design summarizes the existing problems of temporary housing, and proposes modular prefabricated housing that can be assembled and disassembled quickly. It has effectively improved the problems of single space mode, chaotic function, low comfort, poor ecological efficiency and so on. In order to meet the higher comfortableness requirements of the temporary housing, the factory producing, folding loading and unloading and partition are realized. The characteristics of 
economy will be reflected by repeated use, and eventually the sustainable construction of temporary housing will be realized.

\section{Conflicts of Interest}

The authors declare no conflicts of interest regarding the publication of this paper.

\section{References}

Kang, Z., \& Li, X. N. (2013). The Sustainable Strategy of Temporary Housing after the Earthquake. Shanxi Architecture, 39, 13-15.

Li, L. Q. (2008). International Experience in Post Disaster Housing Reconstruction Policy. Disaster Reduction in China, 8, 40-41.

Tang, H. (2008). Construction of Temporary Living Facilities after the Earthquake. New Architecture, 6, 64-68.

Yu, H., \& Liu, M. (2009). Exploration of Modularization and Sustainable Design of Temporary Housing for Disaster Succor and Repertory. Journal of Dalian University of Technology, 49, 714-717.

Zhang, B., Wang, F., \& Zhao, Y. (2008). Post Earthquake Resettlement Settlements Planning Analysis-Taking the Planning of Resettlement Plan in Dujiangyan City as an Example. New Architecture, 6, 69-71. 